\title{
Synthesis and Characterization of Novel Nano Derivatives of Graphene Oxide
}

\author{
Hawraa H. Radey¹, Hadi Z. Al-Sawaad², Moayed N. Khalaf ${ }^{2}$ \\ ${ }^{1}$ Department of Chemistry, College of Science, University of Misan, Misan, Iraq \\ ${ }^{2}$ Department of Chemistry, College of Science, University of Basrah, Basrah, Iraq \\ Email:mariumkarar@yahoo.com
}

How to cite this paper: Radey, H.H., Al-Sawaad, H.Z. and Khalaf, M.N. (2018) Synthesis and Characterization of Novel Nano Derivatives of Graphene Oxide. Graphene, 7, 17-29.

https://doi.org/10.4236/graphene.2018.73003

Received: June 17, 2018

Accepted: July 28, 2018

Published: July 31, 2018

Copyright $\odot 2018$ by authors and Scientific Research Publishing Inc. This work is licensed under the Creative Commons Attribution International License (CC BY 4.0).

http://creativecommons.org/licenses/by/4.0/

(c) (†) Open Access

\begin{abstract}
Graphene oxide has many carboxylic groups within its molecular structure, which is perfect for esterification and imidation, the derivatives graphene oxide GAP, GSO when reaction grapheme oxide with 2-amino pyridine (GAP) and 2-hydroxy-5-sulfobenzoic acid (GSO). These derivatives have been characterized by FTIR, $\mathrm{H}^{1}$ NMR, XRD and FSEM. The patterns of XRD calculated particles size using two equations and compared between them.
\end{abstract}

\section{Keywords}

Derivatives Graphene Oxide, Nanoparticles, X-Ray Diffraction

\section{Introduction}

Graphene oxide is one of the carbon allotropes with a Nano size that gives a high surface area and the ample of oxygenic functional groups that gives the ability to react and join with active or catalysis material [1]. This modification on graphene oxide makes it able to save and generate energy; furthermore, these functional groups give it porous structure, so it could be used as current collector or doped material for electrodes in supercapacitor or lithium batteries [2]. This distinctive nano structure of graphene oxide enables us to use it in various applications like electronics, fuel cells, supercapacitor and sensors. In principle, we can't use graphene oxide in applications that require electric conductivity. This is due to poverty of graphene oxide to electrical conductivity [3]. Graphene oxide is similar to structure of graphite layer, but the plane of carbon atoms in graphene oxide is heavily decorated by oxygen-containing groups [4], GO has many exogenous functional groups such as epoxy (bridging oxygen atoms), hydroxy in the basal plane, carboxyl and carbonyl moieties lining the nanosheet edge [5]. 
In this study, new Nano compound derivative is synthesized from graphene oxide and can be used in several application corrosion inhibitors, solar cell, biological, electronics, etc.

\section{Chemicals}

2-amine pyridine, graphite, Hydrogen peroxide, Potassium permanganate, Sodium nitrate, DCC, DAMP, 7-hydroxy-5-sulfobenzoic acid from Fluka, Hydrochloric acid, Sulphuric acid from BDH.

\section{Synthesis of Graphene Oxide GO, GAP and GSO}

\subsection{Preparation of Graphene Oxide (GO)}

Graphene oxide was prepared according to Hummers [6] method, $2 \mathrm{~g}$ of graphite was added to cool $50 \mathrm{ml}$ concentrated $\mathrm{H}_{2} \mathrm{SO}_{4}$ and stirred in an ice bath for 15 minutes. $1 \mathrm{~g}$ of sodium nitrate and $6 \mathrm{~g}$ of potassium permanganate were added to above solution and stirred in an ice bath for 2 hours. The ice-bath removed and the temperature of the mixture was kept at $35^{\circ} \mathrm{C}$ in water path for $30 \mathrm{mi}$ nutes. After that, the mixture became pasty (deep red-brown in color). $50 \mathrm{ml}$ of deionized water was then added to above mixture. The temperature then raised to $90^{\circ} \mathrm{C}-98^{\circ} \mathrm{C}$. The above mixture was diluted by addition $250 \mathrm{ml}$ warm deionized water. Following this, $30 \% \mathrm{H}_{2} \mathrm{O}_{2}(\sim 30 \mathrm{ml})$ was added till the solution turned bright yellow. The graphite oxide powder was dried at $40^{\circ} \mathrm{C}$ for $24 \mathrm{~h}$ [7] [8] shown in Figure 1.

\subsection{Preparation of GAP}

The GAP derived from GO, mix of grapheme oxide $(0.5 \mathrm{~g})$ with 2-amino pyridine (9.4 g, 9 mmole) dissolved in DMF $100 \mathrm{ml}$ sonicated for $1 \mathrm{~h}$ to form homogeneous solution, then added DCC (2.06 g, 10 mmole), DMAP (1.22 g, 10 mmole). Then the mixture was stirred at $45^{\circ} \mathrm{C}$ for 24 hours. To quench the reaction, an equimolar amount of $\mathrm{HCl}$ was added to the solution to neutralize<smiles></smiles>

Figure 1. Chemical equation of preparation (GO). 
DMAP, after the reaction finish, the product was filter, then black powder was dried [9] shown in Figure 2.

\subsection{Preparation of GSO}

The as-synthesized GO has many carboxylic groups within its molecular structure which is perfect for esterification, First, GO $(0.5 \mathrm{~g})$, with 7-hydroxy-5-sulfobenzoic acid were dissolved in DMF, $100 \mathrm{ml}$ at the room temperature then DCC (2.06 $\mathrm{g}, 10 \mathrm{mmol})$ and DMAP (1.22 $\mathrm{g}, 10 \mathrm{mmol})$ sonicated for $1 \mathrm{~h}$ to form homogeneous solution. The mixture was stirred at $45^{\circ} \mathrm{C}$ for 24 hours. To quench the reaction, an equimolar amount of $\mathrm{HCl}$ was added to the solution to neutralize DMAP the product was filter, then black powder was dried [9] shown in Figure 3.

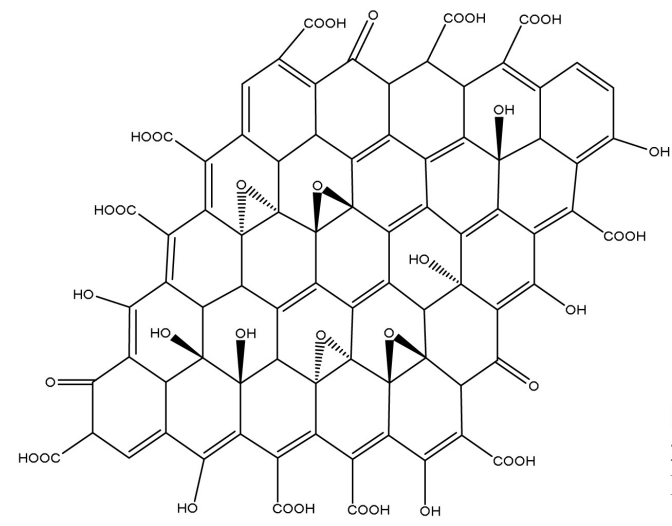

graphene oxide<smiles>Nc1ccccn1</smiles>

2-amino pyridine

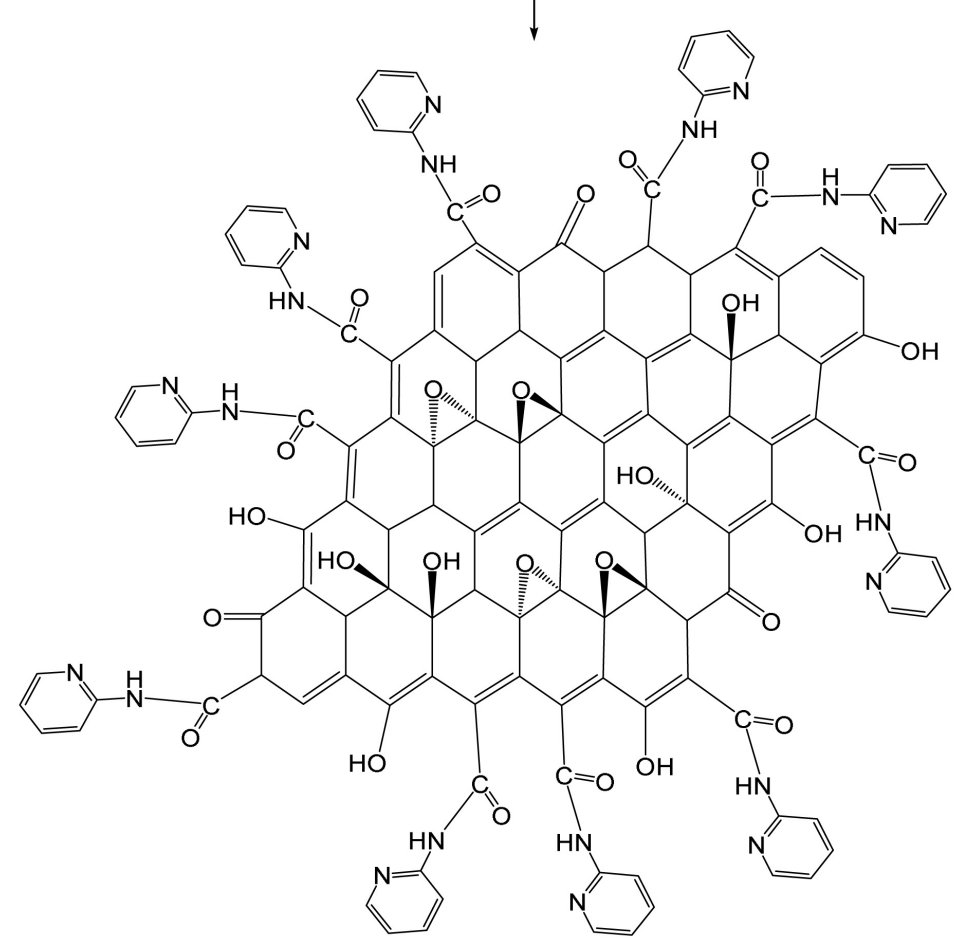

Figure 2. Chemical equation of preparation (GAP). 


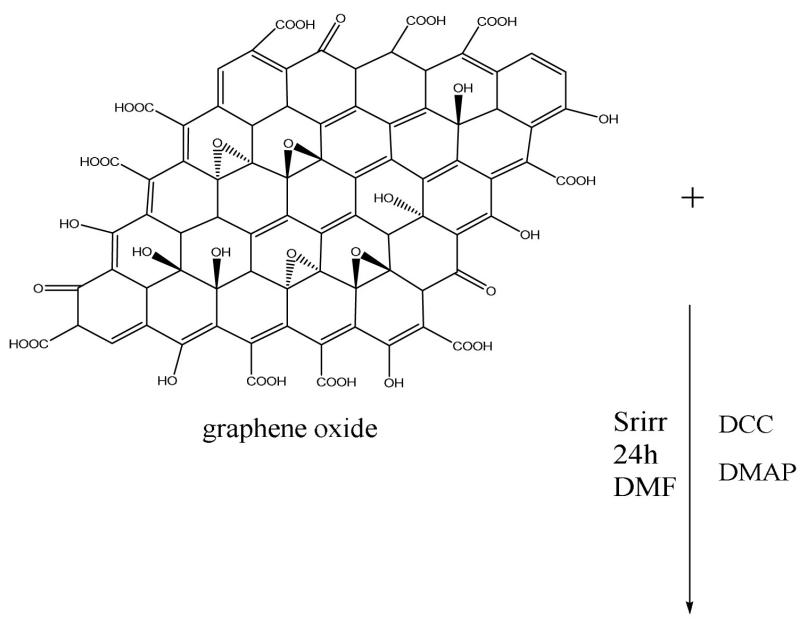

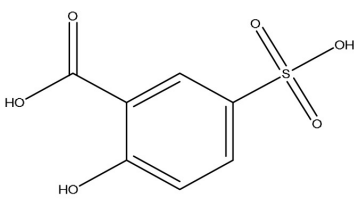

2-hydroxy-5-sulfobenzoic acid

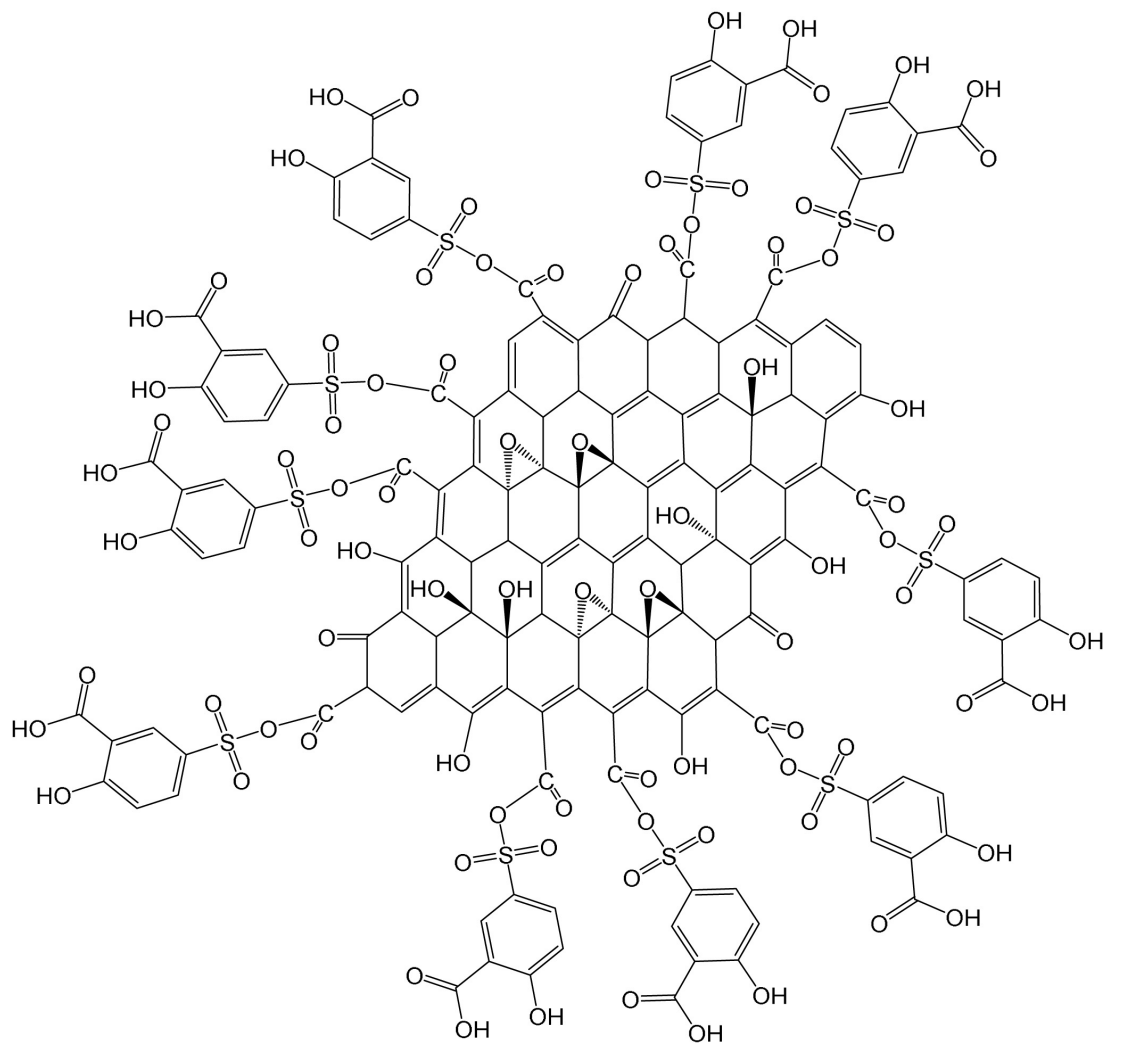

Figure 3. Chemical equation of preparation (GSO).

\section{Characterization Graphene Oxide GO, GAP and GSO}

\subsection{FTIR for GO, GAP and GSO}

FTIR analysis was used to identify functional groups present in the GO, GAP and GSO, Figures 4(a)-(c) show the FTIR spectrum of, GO, GAP and GSO powders respectively, the $\mathrm{GO}$ spectrum shows the peak at $3386.39 \mathrm{~cm}^{-1}$ due to $\mathrm{O}-\mathrm{H}$ stretching vibration, $1724.36 \mathrm{~cm}^{-1}$ was strong $\mathrm{C}=\mathrm{O}$ stretching band, and peak at $16,228 \mathrm{~cm}^{-1}, 1378.85 \mathrm{~cm}^{-1}$ can be attributed to $\mathrm{C}=\mathrm{C}$ stretching of aromatic ring, $\mathrm{C}-\mathrm{OH}$ bending respectively, the characteristic peak at $1029.8 \mathrm{~cm}^{-1}$ due to C-O epoxy group [6]. 


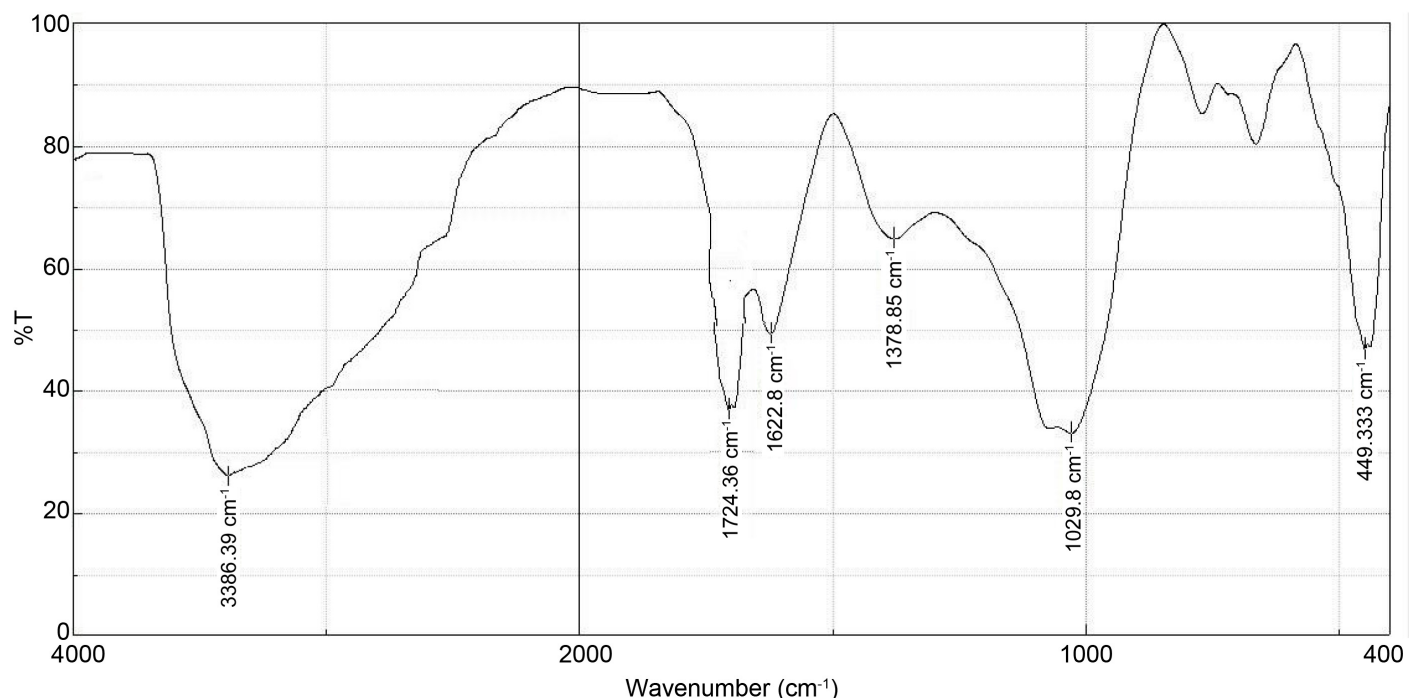

(a)

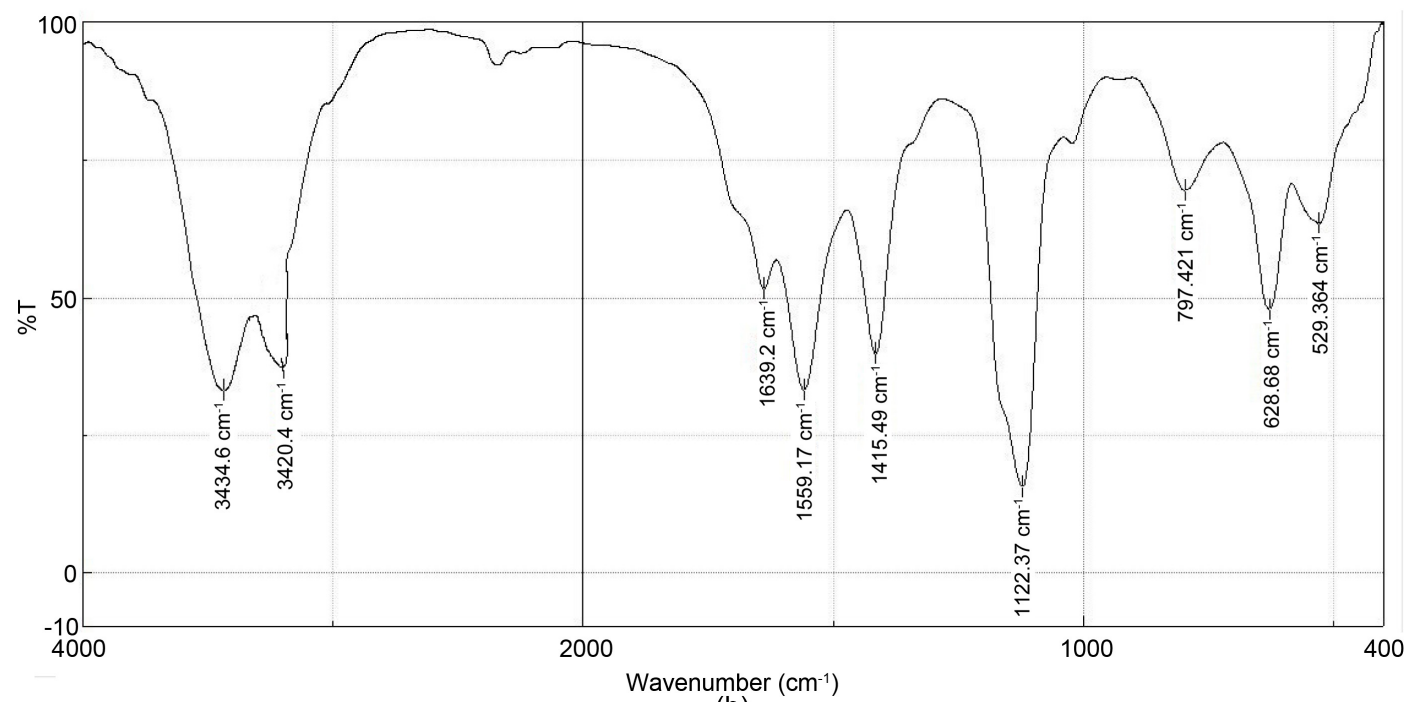

(b)

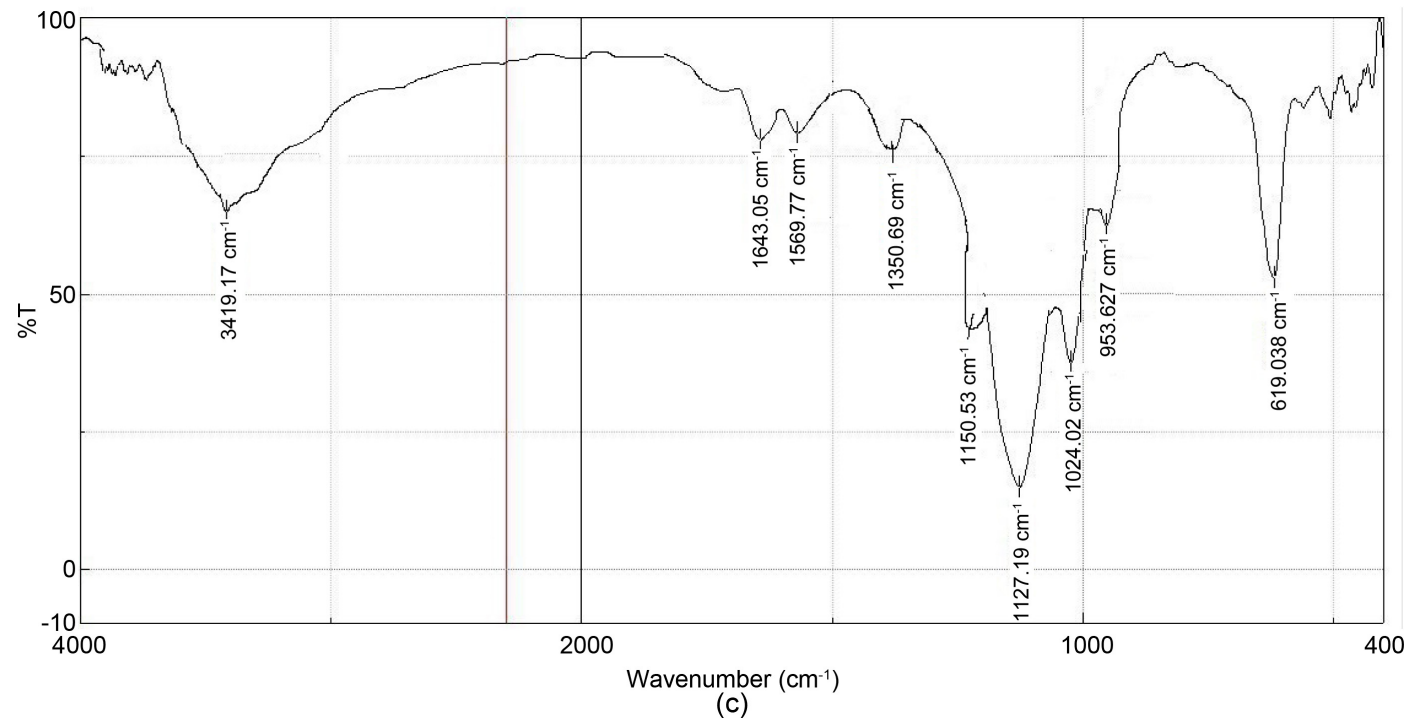

Figure 4. FTIR spectrum of (a) GO powder (b) GAP powder (c) GSO powder. 
Figure 4(b) shows GAP the peak at $3434.6 \mathrm{~cm}^{-1}$ for stretching $\mathrm{OH}$ groups. The presence of absorption bands at $3420.4 \mathrm{~cm}^{-1} \mathrm{~N}-\mathrm{H}$ band, $1639.2 \mathrm{~cm}^{-1}$ due to $\mathrm{C}=\mathrm{O}$ amide stretching vibration , the peak at $1559.17,1415.49,1122.37 \mathrm{~cm}^{-1}$ attributed to $\mathrm{C}=\mathrm{C}$ aromatic ring, $\mathrm{C}=\mathrm{N}$ and $\mathrm{C}-\mathrm{N}$ stretching, also $1029.8 \mathrm{~cm}^{-1}$ due to C-O epoxy group $797.421 \mathrm{~cm}^{-1}$ due to pyridine ring [10].

Figure 4(c) shows GSO the peak at $3419.17 \mathrm{~cm}^{-1}$ for stretching $\mathrm{OH}$ groups, $1643.05 \mathrm{~cm}^{-1}$ due to $\mathrm{C}=\mathrm{O}$ aster stretching vibration, the peak at 1569.77 is attributed to $\mathrm{C}=\mathrm{C}$ aromatic ring, the peaks $1350.69,1150.53 \mathrm{~cm}^{-1}$ assigned to the asymmetric and symmetric of $\mathrm{S}=\mathrm{O}$ bands, also $1127.19,1024.02,953.627 \mathrm{~cm}^{-1}$ due to C-O, epoxy, S-O bending [10].

\section{2. $\mathrm{H}^{1} \mathrm{NMR}$ for GO, GAP and GSO}

$\mathrm{H}^{1}$-NMR spectra of graphene oxide (GO) show the characteristic peaks at (a) at (8.08) $\mathrm{ppm}$ is assigned to the proton of $-\mathrm{COOH}$ groups, (7.50) ppm is singlet assigned to the protons of $\mathrm{OH}$ phenolic groups, the singlet that appear at (7) ppm is assigned to the phenyl groups. All of them is weak and broad because the deshielding of the electron density that yielded by the hydrogen bonding between the layers of GO graphene oxide that leads to reduce the chemical shift of the protons. The singlet, (b) (2.5) ppm is belong to the solvent (c) The peak at (3.75) $\mathrm{ppm}$ is singlet assigned to the $-\mathrm{CH}$ groups that also s group to effect chemical shift [11] (Figure 5(a)).

Figure 5(b) GAP (2.50) ppm is assigned to the solvent, (a) (3.50) ppm is assigned to the $-\mathrm{NH}$ groups. (b) $(7.00-7.50) \mathrm{ppm}$ a multiplet are assigned to the pyridine rings (c) (8.08) $\mathrm{ppm}$ a multiplet due to $\mathrm{H}$-atoms of phenyl groups of $\mathrm{GO}$, and (d) the peaks at (11) ppm is assigned to the phenolic groups in GO because the shielding is reduced from $\mathrm{OH}$ groups by the amidation of $\mathrm{GO}$ with 2-amino pyridine [12].

Figure 5(c) GSO, the peaks at $(2.5,3.5) \mathrm{ppm}$ are assigned to the solvent, (a) (7.0, 7.5, 8.0 and 8.5) ppm due to $\mathrm{H}$-atoms of phenyl groups of both sulphonate ring and GO, of, and (b) (c) the peaks at (12 and 13.0) ppm are singlets assigned to the $\mathrm{H}$ of phenolic (in sulphonate ring and $\mathrm{GO}$ ) of and carboxylic acid groups, respectively [12].

\subsection{X-Ray Diffraction (XDR) of GO, GAP and GSO}

In Figure 6(a), the X-Ray Diffraction (XRD) of grapheme oxide shows a large interlayer spacing equal to $8.06 \mathrm{~A}^{\circ}$ at the position $\left(2 \theta=10.97^{\circ}\right)$ disappearance of the peak at $26^{\circ}$ due to completely oxidized after the chemical oxidation and exfoliation [6].

Figure $6(\mathrm{~b})$ GAP shows that many peaks appear $(2 \theta=10.97)$ at $\mathrm{d}$-spacing 8.06 indicate to graphene oxide and other peaks $2 \theta=32.28,38.78,49.58,76.58$, $59.61,77.28$ and 78.90 have to d-spacing $2.77,2.31,1.83,1.54,1.24,1.23$ and 1.21 , respectively attributed to functionalized 2 -amino pyridine at graphene oxide also intermediate layer [13]. 


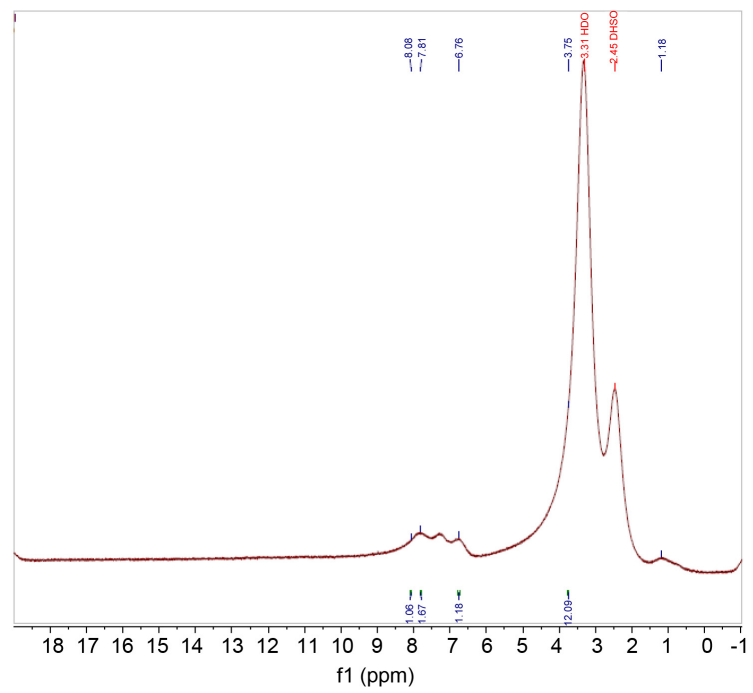

(a)

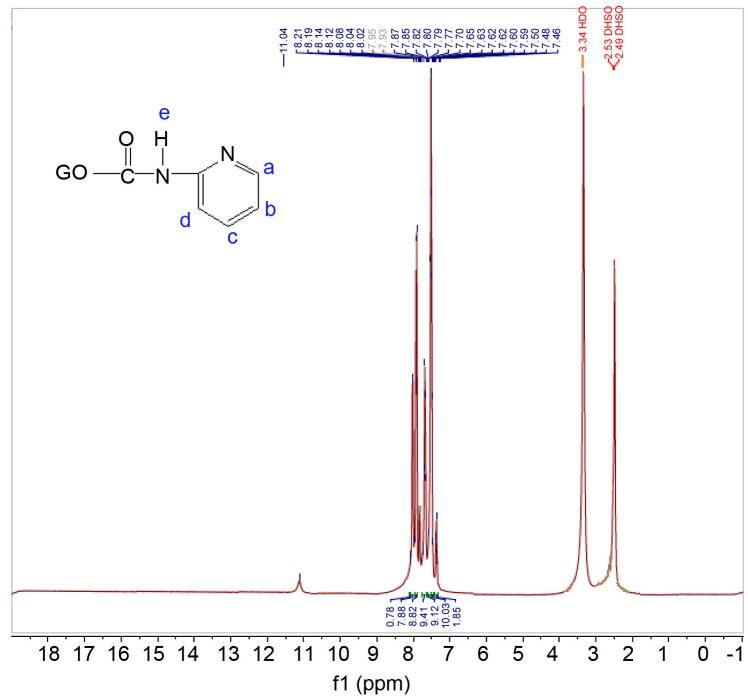

(b)

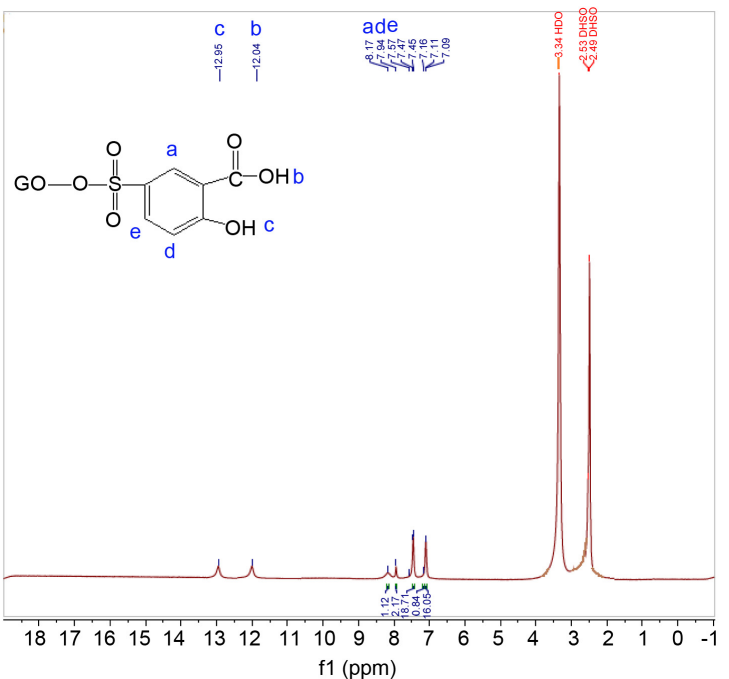

(c)

Figure 5. $\mathrm{H}^{1}$ NMR spectrum of (a) GO (b) GAP (c) GSO. 


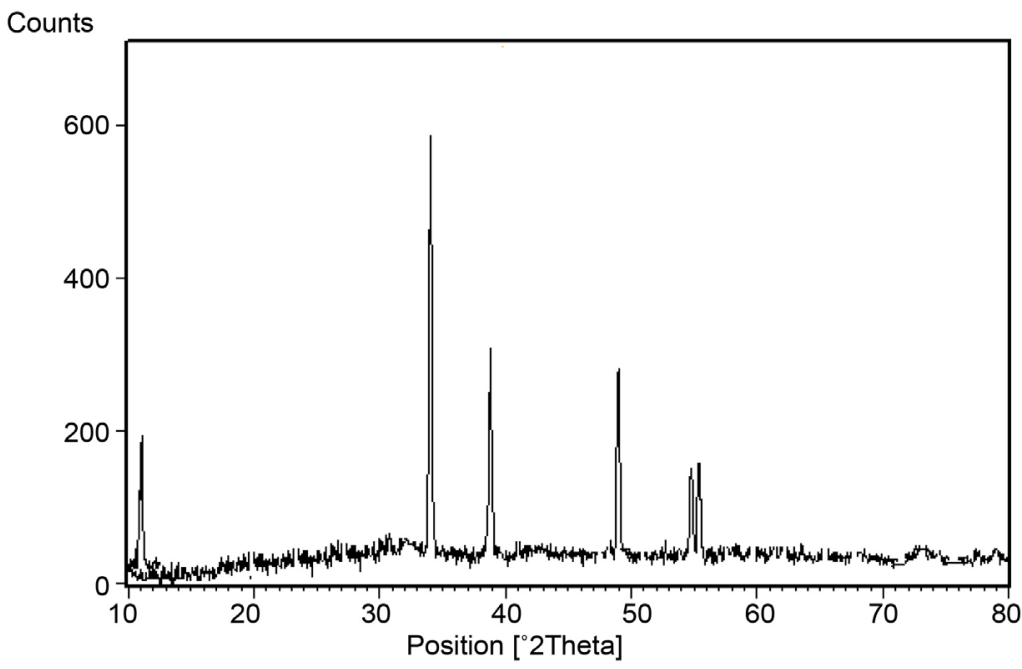

(a)

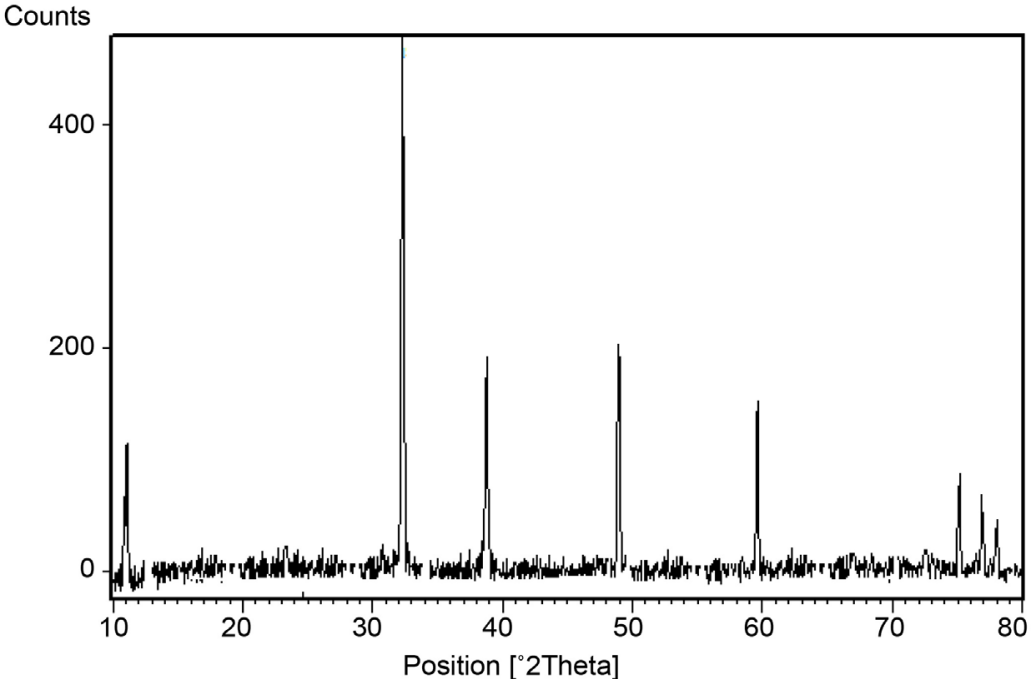

(b)

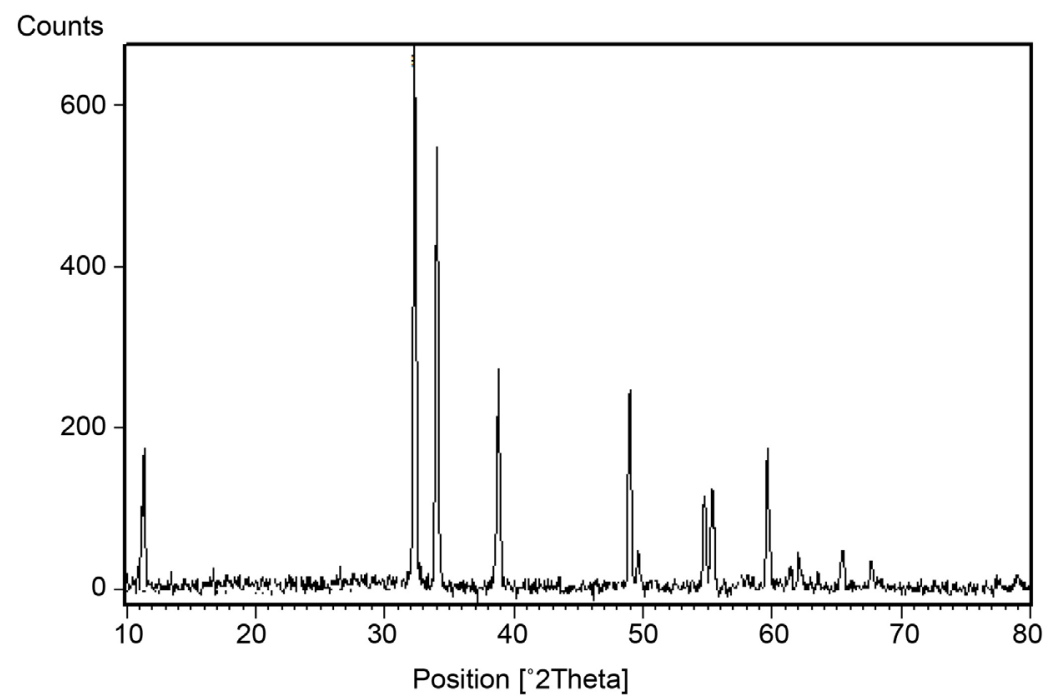

(c)

Figure 6. XRD of (a) GO, (b) GAP, (c) GSO. 
Figure $6(\mathrm{c})$ of GSO shows that many peaks appear $(2 \theta=10.97)$ at d-spacing 8.06 indicate to graphene oxide and other peaks $2 \theta=32.31,34.02,38.80,48.96$, $49.63,57.49,59.62,62.10,65.43$ and 67.68 have to d-spacing $2.77,2.63,1.86$, $1.83,1.60,1.55,1.49,1.42$ and 1.38 , respectively attributed to functionalized 7-hydroxy-5-sulfobenzoic acid at graphene oxide also intermediate layer [13].

The Diffraction patterns of X-ray to prepared organic compound particles size is calculated using (Debye-Scherer) equation [14]

$$
D=\frac{K \lambda}{\beta \cos \theta}
$$

where; $D$ : Particles size, $\lambda$ : X-ray wave length $(\mathrm{nm}), \beta$ : Half width at half maximum (HWHM), $K$ : is s related hape factor, normally taken as 0.9 . $\theta$ is X-ray angle. From this equation the particle size of grapheme oxide (GO) (16 nm) but to calculated average particle size to prepared organic compounds GAP (23.22 nm), GSO $(40.74 \mathrm{~nm})$. Also calculated particles size using (Williamson-Hall) (W-H) equation [15]

$$
\beta \cos \theta=\left[\frac{k \lambda}{D}\right]+[4 \mathfrak{E}+\sin \theta]
$$

where $£$ micro strain of particles, $\lambda$ : X-ray wave length $(\mathrm{nm}), \beta$ : Half width at half maximum (HWHM), $K$ : is s related hape factor, normally taken as $0.9 . \theta$ is X-ray angle where calculated to depend on XRD $\theta$ to compound in Figure 6(b) and Figure $6(\mathrm{c})$. The calculated particles size from graphic between $(\sin \theta)$ on $\mathrm{x}$-axis, $(\beta \cos \theta)$ on $y$-axis, $D$ calculated by intercept $(K \lambda / D)$, Figure 7 , from this equation particles size of GAP $(5.82 \mathrm{~nm})$, and the micro strain $\mathcal{E}$ value was calculated from the Equation (2) GSO (13.69 nm), GAP micro strain (-0.00494), GSO micro strain $(-0.00356)$. The values, $\sin \theta$ and $\beta \cos \theta$, are shown in Table 1.

Table 1. The value $\sin \theta$ and $(\beta \cos \theta)$ GAP, GSO.

\begin{tabular}{cccc}
\hline & GAP & & \multicolumn{2}{c}{ GSO } \\
\hline $\sin \theta$ & $\beta \cos \theta$ & $\sin \theta$ & $\beta \cos \theta$ \\
\hline 0.0095294 & 0.02134 & 0.095294 & 0.009123 \\
0.277159 & 0.01567 & 0.27741 & 0.007654 \\
0.331022 & 0.01345 & 0.291672 & 0.007454 \\
0.418094 & 0.01087 & 0.331186 & 0.007098 \\
0.495671 & 0.00876 & 0.413188 & 0.006231 \\
0.618039 & 0.00654 & 0.418489 & 0.006231 \\
0.622815 & 0.004654 & 0.479569 & 0.005567 \\
0.63378 & 0.004845 & 0.495746 & 0.005432 \\
- & - & 0.514368 & 0.005432 \\
- & - & 0.538993 & 0.005124 \\
- & - & 0.555377 & 0.004876 \\
\hline
\end{tabular}



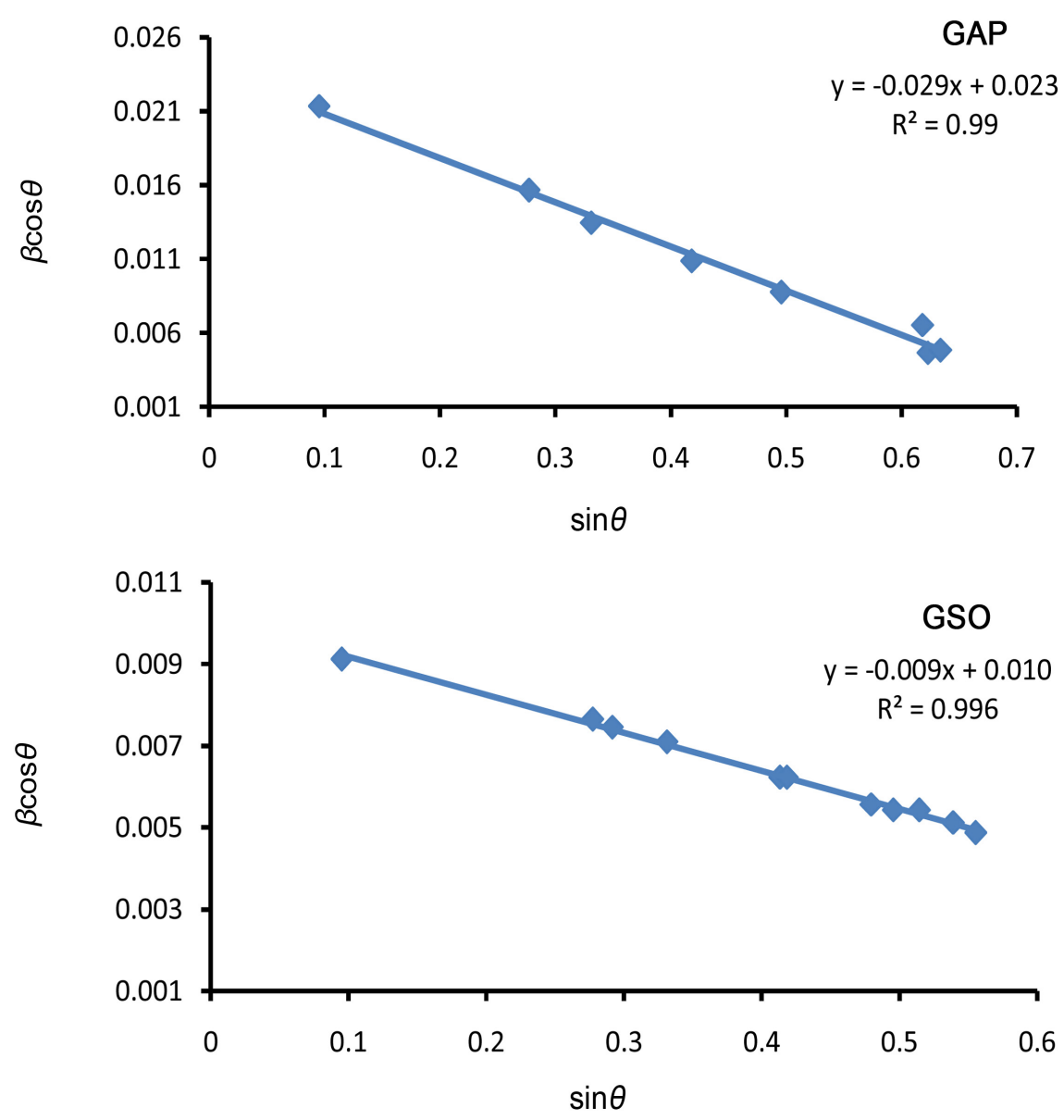

Figure 7. Scheme Williamson-Hall to GAP, GSO.

\subsection{Field Emission Scanning Electron Microscopy (FESEM)}

The FESEM of graphene oxide (GO) very sharp edges and flat surface the dark gray areas consist of several layers of sheets also kinked and wrinkled areas [6] (Figure 8(a)), but GAP appeared relatively coarse very sharp edges and flat surface (Figure 8(b)), GSO the re-stacked layers and crumpling, kinked and wrinkled areas [16] [17] (Figure 8(c)).

\section{Conclusion}

Graphene oxide is synthesized by Hummer method and derivative GAP is prepared by reaction graphene oxide with 2-amino pyridine, GSO when graphene oxide reacts with 2-hydroxy-5-sulfobenzoic acid, graphene oxide and their derivatives characterization by FTIR, H1NMR and XRD. The patterns of XRD calculated particles size using two equations (Debye-Scherer) and (Williamson-Hall) compared between (Debye-Scherer) equation and (William-son-Hall), and the average particles size using (Debye-Scherer) equation high and (Williamson-Hall) to the attributed width peaks to particles size and Internal emotion, which is small when using powders. Also graphene oxide and their derivatives characterize by FESEM observed dark gray areas consist of several layers of sheets and light grey areas represent few layers. 


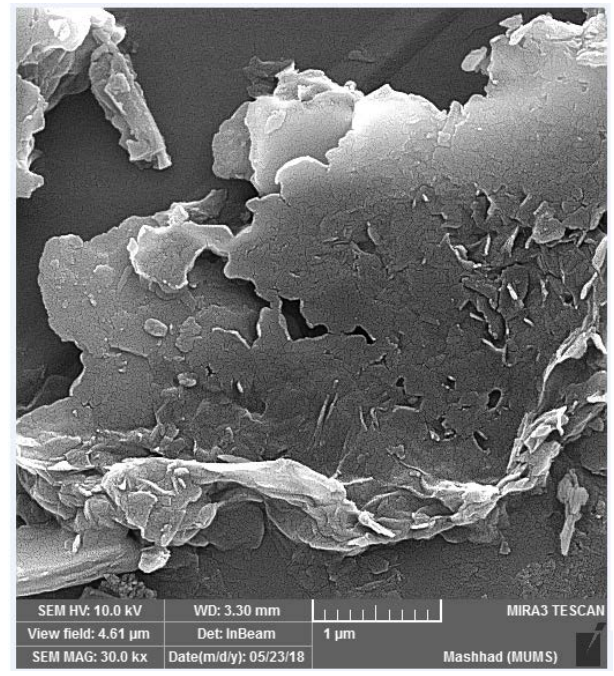

(a)

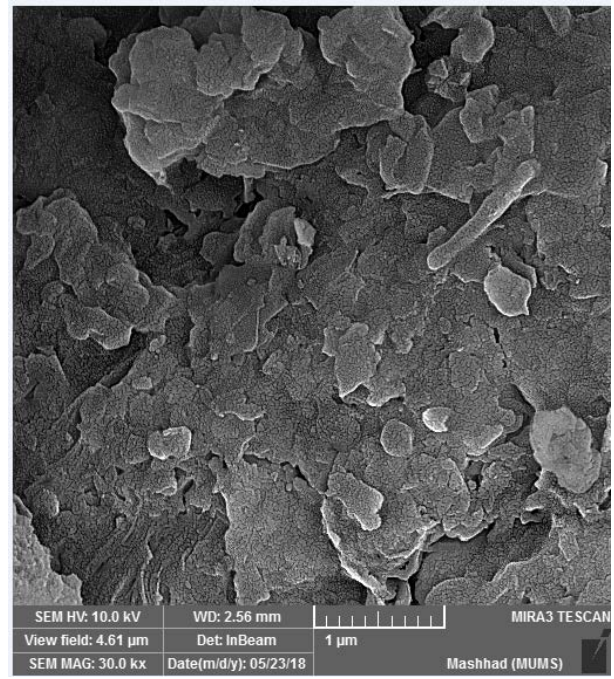

(b)

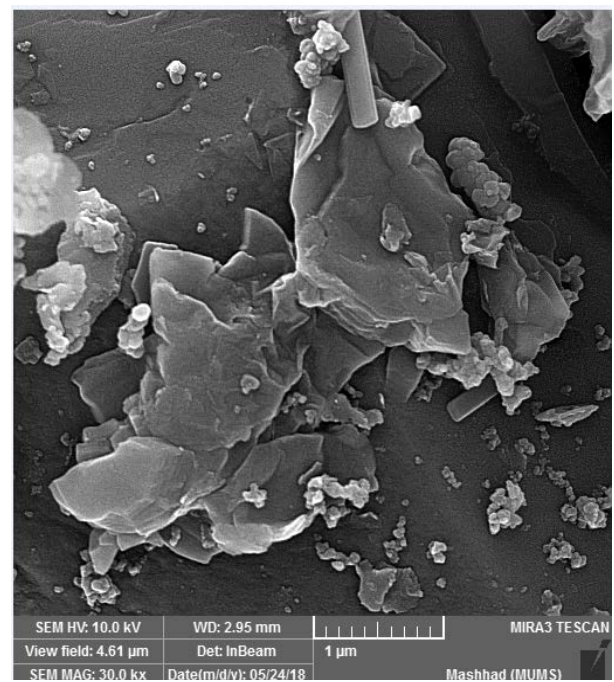

(c)

Figure 8. FESEM of (a) GO, (b) GAP, (c) GSO. 


\section{Conflicts of Interest}

The authors declare no conflicts of interest regarding the publication of this paper.

\section{References}

[1] Hameed, A. (2016) Phosphate Based Cathodes and Reduced Graphene Oxide Composite Anodes for Energy Storage Applications. Chap.1, 25. https://doi.org/10.1007/978-981-10-2302-6

[2] Zhao, J., Liu, L. and Li, F. (2015) Graphene Oxide Physical and Application. Chap. 4, 57-77.

[3] Zabihinpour, M. and Ghenaatian, H.R. (2013) A Novel Multilayered Architecture of Graphene Oxide Nanosheets for High Supercapacitive Performance Electrode Material. Synthetic Metals, 175, 62-67. https://doi.org/10.1016/j.synthmet.2013.04.023

[4] Paulchamy, B., Arthi, G. and Lignesh, B.D. (2015) A Simple Approach to Stepwise Synthesis of Graphene Oxide Nanomaterial. Journal of Nanomedicine \& Nanotechnology, 6, 1000253.

[5] Dreyer, D.R., Park, S., Bielawski, C.W. and Ruoff, R.S. (2010) The Chemistry of Graphene Oxide. Chemical Society Reviews, 39, 228. https://doi.org/10.1039/B917103G

[6] Alheety, M., Mohammed, M. and Jebour, I. (2016) Synthesis and Haracterization of Novel Nano Dithiocarbamate Complexes Derived from GO-Benzimidazole. Dialay Journal for Pure Science, 16, 108-121.

[7] Shahriary, L. and Athawale, A. (2014) Graphene Oxide Synthesized by Using Modified Hummers Approach. International Journal of Renewable Energy and Environmental Engineering, 2, 58-63.

[8] Chammingkwan, P., Matsushita, K., Taniike, T. and Terano, M. (2016) Enhancement in Mechanical and Electrical Properties of Polypropylene Using Graphene Oxide Grafted with End-Functionalized Polypropylene. Materials, 9, 240. https://doi.org/10.3390/ma9040240

[9] Samadaei, Y.F., Salami-Kalajahi, M. and Mamaqani, H. (2016) Radical Coupling of Maleic Anhydride onto Graphite to Fabricate Oxidized Graphene Nanolayers. Bulletin of Materials Science, 39, 229-234. https://doi.org/10.1007/s12034-015-1135-1

[10] Al Juhaiman, L.A. (2016) Polyvinyl Pyrrolidone as a Corrosion Inhibitor for CarbonSteel in HCl. International Journal of Electrochemical Science, 11, 2247-2262.

[11] Chammingkwan, P., Matsushita, K., Taniike, T. and Terano, M. (2016) Enhancement in Mechanical and Electrical Properties of Polypropylene Using Graphene Oxide Grafted with End-Functionalized Polypropylene. Materials, 9, 240. https://doi.org/10.3390/ma9040240

[12] Aldosari, M., Othman, A. and Alsharaeh, E. (2013) Synthesis and Characterization of the in Situ Bulk Polymerization of PMMA Containing Graphene Sheets Using Microwave Irradiation. Molecules, 18, 3152-3167. https://doi.org/10.3390/molecules 18033152

[13] Iram, S. and Hussain, Z. (2015) Covalently Functionalized Graphene Oxide Characterization and its Electrochemical Performance. International Journal of Electrochemistry Science, 10, 9475-9487.

[14] Monshi, A., Foroughi, M., Monshi, R. and Modified, M.R. (2012) Scherrer Equation to Estimate More Accurately Nano-Crystallite Size Using XRD. World Journal of 
Nano Science and Engineering, 2, 154-160.

https://doi.org/10.4236/wjnse.2012.23020

[15] Daud, N. (2017) Functionalizing Graphene Oxide with Alkylamine by Gamma-Ray Irradiation Method. Nanomaterials, 7, 135.

[16] Meng, F., Ishidab, H. and Liu, X. (2014) Introduction of Benzoxazine onto the Grapheme Oxide Surface by Click Chemistry and the Properties of Graphene Oxide Reinforced Polybenzoxazine Nanohybrids. RSC Advance, 4, 9471-9475. https://doi.org/10.1039/c3ra47345g

[17] Al-Saadi, M. and Jihad (2016) Preparation of Graphene Flakes and Studying Its Structural Properties. Iraqi Journal of Science, 57, 145-153. 